\title{
Larvas de helmintos em áreas de recreação de creches de Cuiabá, Mato Grosso
}

\author{
Helminth` larvae in areas of recreation for \\ kindergartens of Cuiaba, Mato Grosso
}

\author{
Arleana do Bom Parto Ferreira de Almeida ${ }^{1}$; Amanda Cavalheiro Cândido²; \\ Valéria Régia Franco Sousa ${ }^{3 *}$
}

\section{Resumo}

No mundo todo milhões de pessoas são acometidas por geo-helmintos, especialmente crianças em idade escolar devido a sua maior exposição a ambientes contaminados. O objetivo deste estudo foi monitorar a contaminação de áreas de recreação de creches por larvas de helmintos ao longo de um ano, mensalmente por técnicas parasitológicas. Nas creches foram colhidas 43 amostras de areia. Em dezessete (39,5\%) amostras foram observadas larvas, sendo $13(76,4 \%)$ filariforme, duas $(11,8 \%)$ rabditiforme e em outras duas $(11,8 \%)$ houve a presença de larvas filariforme e rabditiforme. Os resultados demonstraram maior contaminação nos meses com maior precipitação pluviométrica, evidenciando a necessidade de adoção de medidas de profilaxia nestas áreas.

Palavras-chave: Helmintos, creches, zoonoses, áreas públicas

\begin{abstract}
Around the world millions of people are affected by soil-transmitted helminths, especially school children due to their greater exposure to contaminated environments. The purpose of the present work was to evaluate the contamination of recreation areas from kindergartens with helminth larvae, over a year, monthly for parasitological techniques. In kindergartens were collected 43 samples of sand. In seventeen (39.5\%) samples were observed larvae: 13 (76.4\%) filariforme, two (11.8\%) rhabditiform and other two $(11.8 \%)$ showed the presence of both larvae. The results showed greater contamination in the months with more rainfall, highlighting the need for adoption of measures of prevention in these areas.
\end{abstract}

Key words: Helminths, kindergartens, zoonosis, public areas

\footnotetext{
1 Médica Veterinária. Aluna do Programa de Pós-graduação em Ciências Veterinárias (Nível Mestrado); Departamento de Clínica Médica Veterinária; Universidade Federal de Mato Grosso. E-mail: arleferreira@gmail.com

2 Graduação em Medicina Veterinária pela Universidade Federal de Mato Grosso; Médica Veterinária Autônoma. E-mail: amandacandido.2006@hotmail.com

3 Médica Veterinária. Professora AdjuntoII; Departamento de Clínica Médica Veterinária; Universidade Federal de Mato Grosso. Hospital Veterinário - UFMT; Av. Fernando Corrêa da Costa, s/n. Boa Esperança, Cuiabá - MT, CEP: 78060900. E-mail: regia@ ufmt.br

* Autor para correspondência
} 


\section{Introdução}

A relação entre o homem e os animais domésticos, o cão e o gato, sofre influência de fatores culturais, religiosos e sociais. Os cães têm trazido benefícios para vários segmentos da população, especialmente com crianças, seja como companhia ou em terapia assistida, todavia, essa diversidade de uso dos cães tem facilitado à exposição e a transmissão de várias doenças zoonóticas (MACPHERSON, 2005). Dentre elas, a larva migrans cutânea (LMC) e visceral (LMV), causada respectivamente por Toxocara sp. e Ancylostoma sp (ARAÚJO; RODRIGUES; CURY, 1998).

Ancylostoma caninum tem sido descrito como agente da LMC, e de uma síndrome clínica no homem caracterizada por enterite eosinofílica (McCARTHY; MOORE, 2000). T. canis está associado a manifestações graves com seqüelas como cegueira, quando as larvas infectantes migram para o globo ocular (CASELLA et al. 2001) e o $T$. cati a manifestações gastrointestinais (EBERHARD; ALFANO, 1998). Um fator importante característico do ciclo deste parasito é que os cães jovens eliminam grande quantidade de ovos até um ano de idade (MARTÍNEZ-MORENO et al. 2007). Desta forma, os proprietários de cães e gatos jovens devem iniciar o programa de vermifugação precocemente, além de cuidar com os hábitos higiênicos das crianças (MACPHERSON, 2005).

$\mathrm{O}$ acesso desses animais a áreas públicas, como praias, parques e praças, além de creches e escolas, possibilita a contaminação do solo por suas fezes e freqüentemente por ovos dos diversos helmintos que os parasitam. As infecções por helmintos veiculadas pelo solo são freqüentes e relacionadas à deficiência de condições de saneamento e de educação sanitária. Em todo o mundo cerca de 300 milhões de pessoas são acometidas por geo-helmintos, $50 \%$ desse total são crianças em idade escolar. A alta prevalência em crianças é devido a sua maior exposição, inclusive ao freqüentar caixas de areia em praças públicas, escolas e creches (ALDERETE et al. 2003;
MURADIAN et al. 2005; ARAÚJO; RODRIGUES, CURY, 2008).

Este trabalho teve como objetivo monitorar a contaminação por larvas de helmintos do solo das áreas de recreação de creches municipais de Cuiabá, ao longo de um ano. Entre abril de 2007 a março de 2008 foram colhidas amostras de areia das áreas de recreação de quatro creches municipais das distintas regionais da cidade de Cuiabá. As creches foram selecionadas por apresentarem presença de larvas infectantes em estudo preliminar (ALMEIDA et al. 2007). Foram colhidas amostras mensais de areia (30 gramas) em cinco pontos distintos das áreas de recreação, desprezando a camada superficial do solo. As amostras foram acondicionadas em sacos plásticos estéreis, identificados e armazenados sob refrigeração até o processamento.

O processamento das amostras ocorreu no Hospital Veterinário da Universidade Federal de Mato Grosso. O material foi tamisado em uma peneira de granulometria, processadas pelas técnicas de Hoffmann, Pans e Janer (1934), técnica de Baermann-Moraes, conforme MORAES (1948) e Willis-Mollay (1921) com três repetições. As lâminas confeccionadas foram analisadas em microscopia óptica (objetiva de 40X) para a presença de ovos e/ ou larvas de helmintos.

Nas creches foram colhidas 43 amostras de areia, sendo onze coletas em cada uma das três creches e dez na quarta creche, devido impossibilidade de acessar o parque de recreação por ocasião do recesso escolar.

Em dezessete (39,5\%) amostras foram observadas larvas, sendo $13 \quad(76,4 \%)$ forma filariforme, duas $(11,8 \%)$ rabditiforme e em outras duas $(11,8 \%)$ houve a presença de larvas filariforme e rabditiforme.

Em relação à precipitação pluviométrica (NONO DISTRITO METEREOLÓGICO DE CUIABÁ, 2008) se verificou uma ocorrência maior de creches com larvas nos meses mais chuvosos, com exceção do mês de janeiro, justamente no período de recesso 
escolar (Tabela 1). De acordo com Nunes et al. (2000) o baixo índice pluviométrico e a alta incidência de luz solar podem eliminar as larvas e ressecar ovos de helmintos em ambientes sem proteção adequada, justificando o encontro de maior contaminação das creches nos meses chuvosos.

Tabela 1. Distribuição mensal de contaminação das áreas de recreação de creches municipais de Cuiabá, MT de acordo com a precipitação pluviométrica.

\begin{tabular}{|c|c|c|c|c|c|c|c|c|c|c|c|}
\hline Mês & $\mathrm{Abr} / 07$ & Mai/07 & Jun/07 & Ago/07 & Set/07 & Out/07 & Nov/07 & Dez/07 & Jan/08 & $\mathrm{Fev} / 08$ & Mar/08 \\
\hline $\begin{array}{l}\text { PP } \\
(\mathrm{mm})\end{array}$ & 140,4 & 31,1 & 0,0 & 0,0 & 5,0 & 188,2 & 274,9 & 180,9 & 356,5 & 68,9 & 141,0 \\
\hline Leste & - & - & - & - & - & LF (B) & LF (B) & LF (B) & - & - & $\begin{array}{l}\text { LR e LF } \\
\text { (B) }\end{array}$ \\
\hline Norte & - & - & - & - & - & LR (B) & LR (B) & LF (B) & - & $\begin{array}{l}\mathrm{LF}(\mathrm{B} \mathrm{e} \\
\mathrm{S})\end{array}$ & $\begin{array}{l}\text { LF (B } \\
\text { e S) }\end{array}$ \\
\hline Oeste & - & - & - & - & - & - & - & LF (B) & $\mathrm{NC}$ & LF (B) & $\begin{array}{l}\text { LF (B } \\
\text { e S) }\end{array}$ \\
\hline Sul & - & - & - & - & - & - & - & LF (B) & LF (B) & $\begin{array}{l}\mathrm{LF}(\mathrm{B} \text { e } \\
\mathrm{S})\end{array}$ & $\begin{array}{l}\mathrm{LF}(\mathrm{B} \\
\text { e S) }\end{array}$ \\
\hline
\end{tabular}

PP- precipitação pluviométrica; LF - larvas filariformes; LR - larvas rabditiformes; B - Técnica de Baermann; S - Técnica de Hoffman, Pans e Janer (1934), NC - não coletado.

As creches pesquisadas atendiam em média 80 crianças com faixa etária entre dois e quatro anos de idade. Dessas, três permitiam a utilização do parque apenas no período matutino, em duas não havia troca da areia das áreas de recreação desde a construção; uma a troca ocorrera há um ano e na quarta havia ocorrido apenas a colocação de mais areia no parque de recreação. Nas quatro creches não foi informado a origem da areia utilizada nos parques.

Em três creches foi informada a ocorrência de larva migrans cutânea em período anterior ao estudo e em uma, casos atuais da afecção. Em duas creches foi informada a entrada de animais domésticos no local e em nenhuma se realizava a proteção das áreas de recreação no período noturno, durante as chuvas e da entrada de cães e gatos.

Em dezessete $(39,5 \%)$ amostras foram observadas formas larvares, sendo cerca de 76,5\%
(13) destas infectantes. Associada ao fato das áreas com areia não possuírem proteção aumenta o risco de contaminação por helmintos zoonóticos, já que o acesso de cães e gatos ocorria em pelo menos duas creches. E ainda, as áreas de recreação das creches eram cercadas por muros o que impediria a entrada de cães, mas não de gatos, que têm como hábito enterrar as fezes na areia, contaminando-a com ovos de Ascarídeos e Ancilostomídeos (SANTOS; BONATO; MARQUES, 2003; RODRIGUES et al. 2004).

A ocorrência de casos de larva migrans cutânea pode estar relacionada à contaminação das áreas de recreação das creches, mas também, pode estar associada às condições sanitárias dos domicílios e dos animais de estimação de cada criança, como visto por Leite et al. (2004), que encontrou $45.03 \%$ de positividade para ovos de helmintos em amostras fecais de cães de alunos de instituições de ensino . 
Outro local de infecção poderia ser praças públicas, como observado por Almeida et al. (2007) no município estudado.

O fato das áreas de recreação apresentarem larvas infectantes de helmintos, somado à não adoção de medidas preventivas, como a cobertura destas áreas com lona e a realização de exames da areia, aumentam o risco de contaminação das crianças. Isto demonstra a necessidade de conscientização dos administradores das creches, assim como dos responsáveis pelas crianças sobre estas condições para que adotem tais medidas eficazes de profilaxia.

\section{Referências}

ALDERETE, J. M. S.; JACOB, C. M. A.; PASTORINO, A. C.; ELEFANT, G. R.; CASTRO, A. P. M.; FOMIN, A. B. F.; CHIEFFI, P. P. Prevalence of Toxocara infection in schoolchildren from the Butantã Region, São Paulo, Brazil. Memórias do Instituto Oswaldo Cruz, Rio de Janeiro, v. 98, n. 5, p. 593-597, 2003.

ALMEIDA, A. B. P. F.; SOUSA, V. R. F.; DALCIN, L.; JUSTINO, C. H. S. Contaminação por fezes caninas das praças públicas de Cuiabá, Mato Grosso. Brazilian Journal Veterinary Research and Animal Science, São Paulo, v. 44, n. 2, p. 132-136, 2007.

ARAÚJO, N. S.; RODRIGUES, C. T.; CURY, M. C. Helmintos em caixas de areia em creches da cidade de Uberlândia, Minas Gerais. Revista de Saúde Pública, São Paulo, v. 42, n. 1, p. 150-153, 2008.

CASELLA, A. M. B.; MACHADO, R. A.; TSURO, A.; HATO, M.; COSTA, R.; FARAH, M. E. Seria o Ancylostoma caninum um dos agentes da neurorretinite sub-aguda difusa unilateral (D.U.S.N.) no Brasil? Arquivo Brasileiro de Oftalmologia, São Paulo, v. 64, n. 5, p. 473476, set./out. 2001.

EBERHARD, M. L.; ALFANO, E. Adult Toxocara cati infections in U.S. children: report of four cases. The American Journal of Tropical Medicine and Hygiene, Hanover, v. 59, n. 3, p. 404-406, 1998.

HOFFMANN, W. A.; PONS, J. A.; JANER, J. L. The sedimentation concentration method in schistosomiasis mansoni. Puerto Rico Journal of Public Health Tropical Medicine, Puerto Rico, v. 9, p. 283-291, 1934.
LEITE, L. C.; MARINONI L. P.; CÍRIO, S. M.; DINIZ, J. M. F.; SILVA, M. A. N.; LUZ, E.; MOLINARI, H. P.; VARGAS, C. S. G.; LEITE, S. C.; ZADOROSNEI, A. C. B.; VERONESI, E. M. Endoparasitas em cães (Canis familiares) na cidade de Curitiba - Paraná - Brasil. Archives of Veterinary Science, Curitiba, v. 9, n. 2, p. 9599, 2004.

MACPHERSON, C. N. L. Human behaviour and the epidemiology of parasitic zoonoses. International Journal for Parasitology, Australian, v. 35, n. 11/12, p. 1319-1331, 2005.

MARTÍNEZ-MORENO, F. J.; HERNÁNDEZ, S.; LÓPEZ-COBOS, E.; BECERRA, C.; ACOSTA, I.; MARTÍNEZ-MORENO, A. Estimation of canine intestinal parasites in Córdoba (Spain) and their risk to public health. Veterinary Parasitology, v. 143, n. 1, p. 7-13, 2007.

McCARTHY, J.; MOORE, T. A. Emerging helminth zoonoses. International Journal for Parasitology, Australian, v. 30, n. 12/13, p. 1351-1359, 2000.

MORAES, R. G. Contribuição para o estudo do Strongyloides stercoralis e da estrongiloidose no Brasil. Revista do Serviço Especial de Saúde Pública, Rio de Janeiro, v. 1, p. 507-624, 1948.

MURADIAN, V.; GENNARI, S. M.; GLICKMAN, L. T.; PINHEIRO S. R. Epidemiological aspects of visceral larva migrans in children living at São Remo Community, São Paulo (SP), Brasil. Veterinary Parasitology, Amsterdan, v. 134, n. 1/2, p. 93-97, 2005.

NUNES, C. M.; PENA, F. C.; NEGRELLI, G. B.; ANJO, C. G. S.; NAKANO, M. M.; STOBBE, N. S. Ocorrência de larva migrans na areia de áreas de lazer das escolas municipais de ensino infantil, Araçatuba, SP, Brasil. Revista de Saúde Pública, São Paulo, v. 34, n. 6, p. 656$658,2000$.

RODRIGUES, M. M.; ARAÚJO, A.; MACHADO, D.; FONSECA, F. A. R.; JÚNIOR, M. A. R. A importância das condições de higiene em áreas de recreação infantil. In: CONGRESSO BRASILEIRO DE EXTENSÃO UNIVERSITÁRIA, 2., 2004, Belo Horizonte, Anais... Belo Horizonte, UFMG: 2004. p. 1-7.

SANTOS, R. S.; BONATO, L. C.; MARQUES, M. P. A. Ocorrência de agentes causais de larva migrans em areias destinadas à recreação em escolas de ensino infantil em Espírito Santo do Pinhal, SP, Brasil. Revista Ecossistema, Espírito Santo do Pinhal, v. 28, n. 1/2, p. 57-60, 2003.

WILLIS, H. H. A simple levitation method for detection of hookworm ova. Medical Journal of Australia, North Sidney, v. 8, p. 375-376, 1921. 